\title{
Living upside down: patterns of red coral settlement in a cave
}

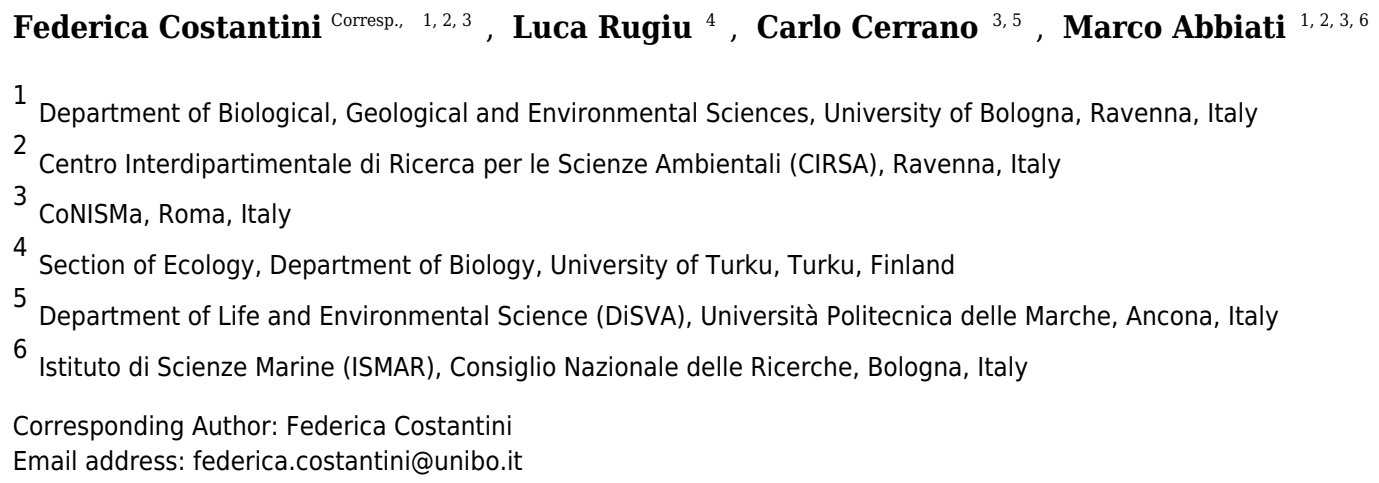

Background. Larval settlement and intra-specific interactions during the recruitment phase are crucial in determining the distribution and density of sessile marine populations. Marine caves are confined and stable habitats. As such, they provide a natural laboratory to study the settlement and recruitment processes in sessile invertebrates, including the valuable Mediterranean red coral Corallium rubrum. In the present study the spatial and temporal variability of red coral settlers in an underwater cave was investigated by demographic and genetic approaches. Methods. Sixteen PVC tiles were positioned on the walls and ceiling of the Colombara Cave, Ligurian Sea, and recovered after twenty months. A total of 372 individuals of red coral belonging to two different reproductive events were recorded. Basal diameter, height, and number of polyps were measured, and 7 microsatellites loci were used to evaluate the genetic relationships among individuals and the genetic structure. Results. Significant differences in the colonization rate were observed both between the two temporal cohorts and between ceiling and walls. No genetic structuring was observed between cohorts. Overall, high levels of relatedness among individuals were found. Conclusion. The results show that $C$. rubrum individuals on tiles are highly related at very small spatial scales, suggesting that nearby recruits are likely to be sibs. Self-recruitment and the synchronous settlement of clouds of larvae could be possible explanations for the observed pattern. 
1 LIVING UPSIDE DOWN: PATTERNS OF RED CORAL SETTLEMENT IN A CAVE

2 COSTANTINI FEDERICA ${ }^{1,2,3}$, RUGIU LUCA ${ }^{4}$, CERRANO CARLO ${ }^{3,5}$, ABBIATI MARCO 2,3,6,7

$3{ }^{1}$ Department of Biological, Geological and Environmental Sciences, University of Bologna, 4 Ravenna, Italy

$5 \quad{ }^{2}$ Centro Interdipartimentale di Ricerca per le Scienze Ambientali (CIRSA), Ravenna, Italy

$6 \quad{ }^{3}$ Universities Consortium for Marine Sciences (CoNISMa), Rome, Italy

$7 \quad{ }^{4}$ Section of Ecology, Department of Biology, University of Turku, Turku, Finland

$8{ }^{5}$ Department of Life and Environmental Science (DiSVA), Università Politecnica delle Marche,

9 Ancona, Italy

${ }^{6}$ Department of Cultural Heritage, University of Bologna, Ravenna, Italy

$11{ }^{7}$ Istituto di Scienze Marine (ISMAR), Consiglio Nazionale delle Ricerche, Bologna, Italy

Corresponding author: federica.costantini@unibo.it

Tel: +390544937401

Fax: +390544973411 


\section{Abstract}

Background. Larval settlement and intra-specific interactions during the recruitment phase are crucial in determining the distribution and density of sessile marine populations. Marine caves are confined and stable habitats. As such, they provide a natural laboratory to study the settlement and recruitment processes in sessile invertebrates, including the valuable Mediterranean red coral Corallium rubrum. In the present study the spatial and temporal variability of red coral settlers in an underwater cave was investigated by demographic and genetic approaches.

Methods. Sixteen PVC tiles were positioned on the walls and ceiling of the Colombara Cave, Ligurian Sea, and recovered after twenty months. A total of 372 individuals of red coral belonging to two different reproductive events were recorded. Basal diameter, height, and number of polyps were measured, and 7 microsatellites loci were used to evaluate the genetic relationships among individuals and the genetic structure.

Results. Significant differences in the colonization rate were observed both between the two temporal cohorts and between ceiling and walls. No genetic structuring was observed between cohorts. Overall, high levels of relatedness among individuals were found.

Conclusion. The results show that $C$. rubrum individuals on tiles are highly related at very small spatial scales, suggesting that nearby recruits are likely to be sibs. Self-recruitment and the synchronous settlement of clouds of larvae could be possible explanations for the observed pattern. 


\section{Introduction}

Recovery and resilience of sessile benthic organisms mostly depend on their early life history stages such as dispersal, settlement and recruitment (Hughes et al., 2000; Pineda et al., 2007). It has been shown that abiotic (Torrents \& Garrabou, 2011) and biotic (Lindsay, Wethey \& Woodin, 1997) factors, as well as larval behaviour (Martínez-Quintana et al., 2014), may influence dispersal and larval mortality during the pre-settlement period. Settlement is influenced by events occurring during the planktonic stage (Babcock \& Mundy, 1996). After settlement, other sources of mortality (e.g. intraspecific competition, predation, detachment from the substrate) can affect the recruitment process (Perkol-Finkel et al., 2008; Santangelo et al., 2012). Larval dispersal and recruitment play a primary role in maintaining genetic diversity, but these processes are stochastic, and may contribute to a chaotic genetic patchiness (Johnson \& Black, 1982). These effects are more evident at fine spatial scales below the expected range of larval dispersal of the species (Eldon et al., 2016). In marine invertebrates chaotic genetic patchiness seems related mainly to high variance in reproductive success (Hedgecock, 1994), collective dispersal (Broquet \& Yearsley, 2012) and asynchronous local population dynamics (Eldon et al., 2016).

Early life stages (from larval release to recruitment) in marine invertebrates such as sponges, ascidians and cnidarians, have been investigated using different tools such as laboratory experiments on larval behaviour (Guizien et al., 2012; Martínez-Quintana et al., 2014), on settlement and metamorphosis on different substrates (Bavestrello et al., 2000), field experiments on settlement and post-settlement processes (Fraschetti et al., 2002), mathematical simulation by biophysical circulation modelling (Guizien et al., 2006), and empirical evidences from population genetics (Hedgecock, Barber \& Edmands, 2007; Eldon et al., 2016). Moreover, 
64 recruitment rates, and their variability in space and time, can be estimated directly, using

65 settlement tiles (Bramanti et al., 2007; Green \& Edmunds, 2011; Santangelo et al., 2012;

66 Bramanti \& Edmunds, 2016); while spatial genetic structure (SGS; e.g. genetic variability,

67 relatedness) can provide indirect estimates of recruitment patterns and variability (Brazeau,

68 Sammarco \& Atchison, 2011; Smilansky \& Lasker, 2014). The strong SGS observed in

69 Anthozoa suggest that recruitment is often local, probably as a result of the short effective

70 dispersal of larvae (Costantini, Fauvelot \& Abbiati, 2007a; Ledoux et al., 2010a). Recruitment

71 coming only or mostly from local populations (self-recruitment) can lead to an impoverishment

72 of the genetic variability and thus decreasing the population's resilience to stressors (Brazeau,

73 Sammarco \& Atchison, 2011; Lasker, 2013) but could also enhance population survival through

74 local adaptation (Sanford \& Kelly, 2011). However, to date, only few studies have analysed the

75 SGS in coral settlers and recruits (Brazeau, Sammarco \& Atchison, 2011; Torda et al., 2013;

76 Smilansky \& Lasker, 2014).

77 Underwater caves (sensu Rastorgueff et al., 2015) represent a naturally fragmented and confined

78 habitat not exposed to the strong currents, which often provide a natural protection from

79 disturbances associated with waterborne substances (Garrabou \& Harmelin, 2002). Due to their

80 high species richness, caves are considered a Mediterranean biodiversity reservoir

81 (Gerovasileiou \& Voultsiadou, 2012). Underwater caves represent, therefore, an excellent natural

82 mesocosm to investigate the recruitment processes without adding other stochastic external

83 disturbances. Moreover, the understanding of recruitment processes in cave species assemblages

84 will be pivotal to forecast their ability to recover after disturbances, and to understand if they can

85 act as refugia for populations living outside the caves. 
86 The red coral (Corallium rubrum L. 1758) is one of the abundant species inhabiting

87 Mediterranean caves due to its preference for dim-light conditions and downwards-facing 88 surfaces (Laborel \& Vacelet, 1961; Garrabou \& Harmelin, 2002; Virgilio, Airoldi \& Abbiati, 89 2006). Red coral is a gonocohoric species with internal fertilization. Gonadal development 90 follows an annual cycle with a synchronized release in summer (Santangelo et al., 2003). 91 Planulae are internally brooded and released once a year over a period of approximately 2 weeks between the end of July and early August (Santangelo et al., 2003; Bramanti et al., 2005). C. rubrum populations are thratened by several stressors: smothering by sediments, harvesting 94 (Tsounis et al., 2013), climate change (Bramanti et al., 2013; Cerrano et al., 2013), heat waves

(Cerrano, Bavestrello \& Bianchi, 2000). Several recruitment studies using settlement tiles have been carried out on shallow-water red coral populations inhabiting vertical cliffs or small crevices (Bramanti, Magagnini \& Santangelo, 2003; Bramanti et al., 2007; Santangelo et al., 2012). High variability in the density of recruitment between different sites has been found, and has been attributed to biological interactions (e.g. competition for space, predation, overgrowth) (Bramanti, Magagnini \& Santangelo, 2003; Santangelo et al., 2012). Population genetic studies, conducted only on adult colonies, have shown large heterozygosity deficiencies, suggesting the occurrence of inbreeding (non-random mating) within populations (Costantini, Fauvelot \& Abbiati, 2007a,b, Ledoux et al., 2010b,a; Aurelle et al., 2011) and a strong genetic structure at distances of less than one meter (Costantini, Fauvelot \& Abbiati, 2007a; Ledoux et al., 2010a). In the present study we investigated two cohorts of red coral recruits on settlement tiles deployed in a Mediterranean submarine cave acting as an experimental mesocosm. Specifically, we have analysed the variability of biometric parameters of the two cohorts of settlers (e.g. abundance of settlers, diameter, height, number of polyps). By means of microsatellite loci, the relatedness and 
109 the fine spatial genetic structure within and between the two cohorts have been analysed in order

110 to provide additional information on early life characteristics and population dynamics of this

111 species. Understanding red coral recruitment processes is of key importance to unveil the drivers

112 of the population dynamics of the species and hence the potential recovery of the 113 overexploited/threatened populations.

\section{Materials and methods}

Study area and experimental design

117 The study was conducted inside the Colombara (or Marcante) cave (Lat $44^{\circ} 18^{\prime} 35^{\prime \prime} \mathrm{N}$, Long $9^{\circ}$ $11810^{\prime} 37 "$ E) located on the east coast of the Gulf of San Fruttuoso (Italy). The cave, 10 meters 119 long, stands from 34 to $39 \mathrm{~m}$ depth on a rocky cliff southward oriented. The cave walls host a 120 rich assemblage of sessile invertebrates typical of the sublittoral caves of the northwest Mediterranean Sea (Morri et al., 1986) with many sponges, corals, bryozoans, polychaetes, and 122 tunicates.

Field experiments were approved by the Marine Protected Area of Portofino and by the Università Politecnica delle Marche (Authorization n. 3/2011 (n. prot. 449/2-1-5.) and authorization $n^{\circ}$ 4/2012 (Protoc. $\left.N^{\circ} 409 / 2-1-1\right)$ ).

In June 2010, about 3 weeks before the start of red coral spawning (Santangelo et al., 2003),

127 sixteen $20 \times 20 \mathrm{~cm}$ white PVC tiles, drilled in the centre, were fixed inside the cave by steel screws. PVC was selected owing to the success in previous experiment on larval recruitment

129 (Cerrano C, pers. comm; but see also Kennedy et al., 2017). Moreover, having positive 130 buoyancy, the risk of detachment from the ceiling was avoided. 
131 In order to test if recruitment is affected by orientation, one plot of four tiles was located on the

132 right vertical wall, another plot on the left vertical wall, and two plots on the ceiling of the cave

133 (Fig. 1). Each tile was attached to the rock, $1 \mathrm{~m}$ from the entrance and at a minimum distance of

$13430 \mathrm{~cm}$ from any another tiles, to avoid possible mutual interference. The red coral population

135 distribution into the cave is patchy, showing an average density of $349 \pm 215 \mathrm{col} / \mathrm{m}^{2}$ (Cattaneo-

136 Vietti, Bavestrello \& Senes, 1993). Tiles were attached in low-density areas of the red coral

137 population trying to limit as much as possible the breakage of surrounding colonies.

138 In February 2012, after two reproductive events (summer 2010 and summer 2011), the tiles were

139 removed ( $\mathrm{n}=14$ as 2 located on one vertical wall were lost, Fig. 1). Recovered tiles were fixed in

$14080 \%$ ethanol and transferred to the laboratory. A picture of each tile was taken with a NIKON

141 camera on a stereomicroscope NIKON SMZ 1500 and analysed with IMAGE J software version

$1421.24 \mathrm{o}$ (http://imagej.nihgov/ij) to study the spatial distribution of the red coral individuals. The

143 position of each individual was marked and size (diameter) was measured by averaging the

144 minimum and maximum width. All the individuals were then removed from the tiles and for

145 each of them; the number of polyps was counted under the dissecting microscope. Polyps were

146 removed from each individual and stored in plastic tubes with $80 \%$ ethanol at $4^{\circ} \mathrm{C}$ for the

147 subsequent DNA extraction.

148 Based on the literature on red coral early life stages (Bramanti et al., 2005) the age of each 149 individual was estimated on the basis of its height: individuals with an encrusting button shape 150 and colonies with height equal to zero were assigned to the cohort 2011 (hereafter recruits); 151 individuals that developed in height forming a small branch were assigned to the cohort 2010 152 (hereafter juveniles) (Fig. 2). 
153 To check if a sort of cave-effect affected the pattern of recruitment, in the same period an 154 additional series of plots with four PVC tiles were deployed on a vertical cliff out of the cave 155 (Punta del Faro) where the red coral population has the same range of density as that of the cave $156\left(425 \pm 100\right.$ colonies $\left.\times \mathrm{m}^{2}\right)($ Bavestrello et al., 2015). Plots were fixed at 35, 45, 55 and $70 \mathrm{~m}$ 157 depth.

158

159

160

161

162

163

164

165

166

167

168

169

170

171

172

173

174

175

\section{Measuring growth performances}

The size structure of red coral individuals was obtained by analysing the frequency distributions of the basal diameter (for both recruits and juveniles) and of colony height (only for juveniles).

The correlations between the parameters (diameter vs. height; diameter vs. number of polyps; height vs. number of polyps) were analysed by Pearson's coefficient. Moreover, we tested the temporal and spatial variations of the abundance of individuals by two separate one-way ANOVAs based on 9999 permutation with Cohort (two levels; fixed; recruits and juveniles) and Position (two levels; fixed; ceiling and walls) as factors using PRIMER v6 software program (Clarke \& Gorley, 2006)

\section{Measuring genetic variability and structuring}

Due to the small number of $C$. rubrum individuals found on the tiles deployed on the walls, the molecular analysis was carried out only on the individuals occurring on the tiles deployed on the ceiling of the cave.

Total genomic DNA was extracted from each individual (1 to 4 polyps per colony) following the CTAB protocol and purified by standard chloroform procedure. Seven microsatellite loci COR9, COR46, L7, COR58, MIC20, MIC24, MIC26 (Costantini \& Abbiati, 2006; Ledoux et al., 2010b) 
176 were amplified either as single locus using the protocol by Costantini \& Abbiati, (2006) and by

177 Ledoux et al., (2010b) or in multiplex using a QIAGEN Multiplex PCR Kit. Genotyping was

178 performed by MACROGEN INC. Allele sizing was determined with Peak Scanner v1.0

179 software. Genotypic linkage disequilibrium at each pair of loci for each was tested using FSTAT

180 v.2.9.3.2 (Goudet, 2001). Significance of each pairwise comparison was tested using 3360

181 permutations of the data.

182 Scoring errors due to stuttering, large allele dropout and null alleles were controlled with

183
MICROCHECKER version 2.2.3 (Van Oosterhout et al., 2004). Estimated frequencies of putative null alleles were subsequently calculated for each locus using the expectation maximization (EM) algorithm of Dempster, Laird \& Rubin, (1977) implemented in FREENA (Chapuis \& Estoup, 2007). Red coral settlers sharing the same multilocus genotype (MLG) were identified using GENALEX version 6.1 (Peakall \& Smouse, 2006). Identical MLGs can result from two distinct sexual reproduction events. To test this, the unbiased probability of identity ( $\left.\mathrm{P}_{\mathrm{ID}}\right)$ that two sampled individuals shared identical MLG by chance (Kendall \& Stewart, 1977) was computed. The total number of alleles $\left(\mathrm{N}_{\mathrm{a}}\right)$, observed $\left(\mathrm{H}_{\mathrm{o}}\right)$, and unbiased expected $\left(\mathrm{H}_{\mathrm{e}}\right)$ heterozygosities (Nei, 1973) were calculated for each locus and for each cohort of settlers (either recruits and juveniles) using GENETIX software package version 4.03 (Belkhir et al., 2000). Allelic richness (Ar) was calculated after controlling for differences in sample size using a rarefaction approach implemented in HP rare with a common sample size of 54 settlers (Kalinowski, 2005). The $f$ estimator of $\mathrm{F}_{\mathrm{IS}}$ (Weir \& Cockerham, 1984) was computed, and significant departures from the Hardy-Weinberg equilibrium were tested using Fisher's exact test in GENEPOP version 3.4 (http://genepop.curtin.edu.au/; Raymond \& Rousset, 1995), with the level of significance determined by a Markov chain randomization. Significant differences in 
199

200

201

202

203

204

205

206

207

208

209

210

211

212

213

214

215

216

217

218

219

220

genetic diversity $\left(\mathrm{H}_{\mathrm{o}}, \mathrm{H}_{\mathrm{e}}\right.$ and Ar) between recruits and juveniles were tested using a Student's ttest. For all the analyses, when necessary, a correction for multiple tests was applied with a false discovery rate of 0.05 (Benjamini \& Hochberg, 1995).

To determine whether individuals were more related than expected under panmixia, the $\mathrm{R}_{\mathrm{XY}}$ pairwise relatedness coefficient (Queller \& Goodnight, 1989) was computed separately for recruits and for juveniles. This index varies between 0 and 0.5 with $\mathrm{R}_{\mathrm{XY}}=0.5$ for full-sib relationships, $\mathrm{R}_{\mathrm{XY}}=0.25$ for half-sibs and $\mathrm{R}_{\mathrm{XY}}=0$ for unrelated individuals in an infinitely large panmictic population (Peakall \& Smouse, 2006). The observed mean and variance of $\mathrm{R}_{\mathrm{XY}}$ were compared with their expected distribution under the null hypothesis of panmixia using 1000 permutations of alleles as implemented in IDENTIX (Belkhir, Castric \& Bonhomme, 2002). The null distribution was obtained by a conventional Monte Carlo resampling procedure, which randomly selected 10,000 genotypes without replacement and then recalculating the statistic.

Null hypothesis could be rejected with a significance level of $5 \%$, given that the observed value of the statistic was above the $95 \%$ level of the resampled statistics.

An exclusion test, performed in GENECLASS 2.0 (Piry et al., 2004), was used to test whether individuals found in one tile was more similar to the individuals settled on the same tile. First, the likelihood that an individual belonged to a particular tile was computed with a Bayesian criterion of Rannala \& Mountain (1997). Then, this likelihood was compared to a distribution of likelihoods of 10000 genotypes simulated from each candidate tile with a Monte Carlo algorithm. An individual was excluded from its tile when the probability of exclusion was greater than $95 \%$ ( $\mathrm{P}$ or $\alpha \leq 0.05$ ). The second part of this Bayesian analysis utilized the probabilities that the individuals excluded from their sampling tile originated from one of the 
221 other tiles. Thus, individuals that were excluded from their sampling tile when $\mathrm{P} \leq 0.05$, were

222 assigned to another tile when $\mathrm{P} \geq 0.1$.

223 The value of effective population size $(\mathrm{Ne})$ for each cohort was inferred using the standard

224 linkage disequilibrium method with Waples (2006) correction. The computations were

225 performed with LDNe under the random-mating model, excluding rare alleles with frequencies

226 of less than 0.02 and using the Jackknife option to estimate confidence intervals (Waples \& Do,

$2272008,2010)$.

228 To account for unbalanced sample sizes between the recruits and juveniles, genotypic 229 differentiation was tested with an exact test (Markov chain parameters: 1,000 dememorizations, 230 followed by 1,000 batches of 1,000 iterations per batch), and the $\mathrm{P}$ value of the log-likelihood 231 (G)-based exact test (Goudet et al., 1996) was estimated in GENEPOP.

232 A Bayesian approach implemented in the program STRUCTURE version 2.2 (Pritchard, 233 Matthew \& Donnelly, 2000; Falush, Stephens \& Pritchard, 2007) was used to estimate the 234 number of genetic clusters, K, within the entire sample (i.e. recruits + juveniles). Mean and 235 variance of log likelihoods of the number of clusters for $K=1$ to $K=10$ were inferred by 236 running structure ten times with 1000000 repetitions each (burn-in $=100000$ iterations) under the

237 238 239

admixture ancestry model and the assumption of correlated allele frequencies among samples. Due to the presence of null alleles, the clustering analysis was conducted on the original data set, using the option of null alleles coded as recessive alleles described in Falush, Stephens \& Pritchard, (2007). Mean likelihoods of $\mathrm{K}$ from ten runs were plotted using STRUCTURE HARVESTER 0.56.3 (available at http://taylor0.biology.ucla.edu/struct_harvest/). Results of all runs were averaged in CLUMPAK server (Kopelman et al., 2015). Moreover, since the Structure analysis could be inflated by the HW disequilibrium, a discriminant analysis of principal 
244 components (DAPC), available in the Adegenet package (Jombart, Devillard \& Balloux, 2010)

245 for R (R Development Core Team, 2012), was also performed. This technique is designed for

246 multivariate genetic data (multi-locus genotypes). It maximizes the variation between groups by

247 first performing a principal component analysis (PCA) on pre-defined groups or populations and

248 then uses the PCA factors as variables for a discriminant analysis (DA), thus ensuring their

249 independence.

250 Spatial autocorrelation analyses among individuals were performed with SPAGEDI (Hardy \&

251 Vekemans, 2002). The Loiselle's kinship coefficient ( $\phi i j$; Loiselle et al., 1995) was used since it

252 is not dependent on Hardy-Weinberg (HW) equilibrium conditions (Hardy, 1999) and it has

253 been proven to be very effective in determining spatial genetic structure (Vekemans \& Hardy, 254 2004). Two different analyses were performed. To test the spatial autocorrelation within the 255 cave, distance categories were set based on the distance between tiles and considering the 256 distance between two individuals found within the same tile as zero. Then, spatial 257 autocorrelation analyses within those tiles containing more individuals (T4, T5, T7, T8, T9 and 258 T10; see results) were carried out. Taking into account the distance between individuals, the 259 distance categories were set in such a way that the number of pairwise comparisons within each distance category was approximately constant. Statistical significance was based on permuting 261 individual locations among all individuals 10000 times and calculating upper and lower 95\% 262 confidence interval for each distance class.

Results 


\section{Red coral recruitment}

In the plots positioned into the cave, 372 individuals were observed on the 14 tiles. Corallium rubrum settled on every tile deployed on the ceiling of the cave, but recruitment failed on three out of eight tiles on the walls (T1, T13, T14). In fact, of the 372 individuals, 350 were found on the ceiling tiles, and only 22 on the tiles deployed on the walls, corresponding to a significantly higher density on the ceiling than on walls (ANOVA: $\mathrm{F}_{1,14}=10.78 ; \mathrm{P}<0.01$, Fig. 3 ). Of the 350 individuals on the ceiling, 278 were recruits and 72 were juveniles, corresponding to a density of $34.75 \pm 23.86 / 400 \mathrm{~cm}^{2}$ and of $9 \pm 6.82 / 400 \mathrm{~cm}^{2}$, respectively $\left(A N O V A: F_{1,26}=5.99 ; \mathrm{P}<0.05\right.$ Fig. 2). The 22 individuals found on the wall were all recruits (Fig. 3). On the tiles positioned along the vertical cliff, at all depths no recruits were found when checked in summer 2011.

\section{Growth performances}

The size/recruit structure showed a monotonic and decreasing pattern, in which recruits in the first class (recruits with diameter $<1.5 \mathrm{~mm}$ ) represented the dominant class (Fig. 4A). Only three recruits $(1 \%)$ had a diameter $>6 \mathrm{~mm}$, and they might have been formed by merging of two or more planulae (Fig. 2) as observed by Cerrano C, (pers. comm.). The number of polyps per recruit ranged from 1 to 22 , with $70.66 \%$ of the recruits presenting $1-2$ polyps, $22 \%$ between $3-4$ polyps and $7.33 \%$ more than four polyps (mean $\pm \mathrm{SD}=2.3 \pm 2.1$ polyps/recruit). Pearson's coefficient showed a low correlation between these two variables $(r=0.4)$ (Fig. 4C).

The size structure of juveniles showed a more variable trend, with diameter values ranging from $0.15 \mathrm{~mm}$ to $8.95 \mathrm{~mm}$ with an average value of $2.5 \pm 1.5 \mathrm{~mm}$ (Fig. 5A). The number of polyps ranged from 0 to 22 (average number of 9.21 \pm 4.6) (Fig. 5C). Juveniles with 3-4 polyps were $9.7 \%$ of the total number, while $90.3 \%$ had more than five polyps. The height of the juveniles 
ranged from 0.5 to $9.15 \mathrm{~mm}$, with a mean of $3.3 \pm 1.8 \mathrm{~mm}$ (Fig. 5E). Pearson's correlation coefficients showed no correlation between diameter and number of polyps $(\mathrm{r}=0.09$, Fig. 5B), nor between diameter and height $(\mathrm{r}=0.03$, Fig. 5F). A weak correlation between height and number of polyps was observed $(r=0.3$, Fig. 5D).

\section{Genetic variability}

Individuals in which more then two loci did not amplify due to technical failures (e.g. low DNA quantity, no amplification of after re-amplification) were not included in the dataset. A total of 290 red coral individuals were genotyped. No genotypic disequilibrium was observed between loci (all $\mathrm{P}>0.05$ after FDR correction). No evidence of scoring errors due to stuttering or large allele dropout was found, according to MICROCHECKER. An excess of homozygotes was detected at all loci due to the presence of null alleles. Null allele frequencies ranged from 0.09 (Mic24) to 0.25 (Cor9, Mic26 and Cor58). Number of alleles ranged from 10 (Mic20) to 23 (Cor9 and Mic26). The expected and observed heterozygosity ranged from 0.29 (Cor46) to 0.81(Cor9) and from 0.13 (Mic26) to 0.64 (Mic20), respectively. The estimators of $\mathrm{F}_{\text {IS }}(f)$ were positive and ranged from 0.21 (Mic20) to 0.86 (Cor48) (Table 1).

Overall, a low genetic variability $\left(\mathrm{H}_{\mathrm{e}}=0.59 \pm 0.16\right.$ and $\mathrm{H}_{\mathrm{o}}=0.29 \pm 0.2$; mean $\left.\pm \mathrm{SD}\right)$ was found. Out of the 290 individuals analysed, 281 different multilocus genotypes (MLGs) were identified. Four MLGs were found twice; one MLG was encountered three times and one four times. Individuals sharing the same MLG always came from the same tile. Tiles where identical MLGs were found were T7, T8 and T10. The individuals sharing the same MLG were between $0.2 \mathrm{~cm}$ and $13.65 \mathrm{~cm}$ apart (in $\mathrm{T} 7$ and T10, respectively). In T8 and T10, one recruit and one juvenile 
310 shared a MLG. The unbiased probability of identity $\left(\mathrm{P}_{\mathrm{ID}}\right)$ that two sampled individuals share

311 identical MLG by chance was $1.5 \mathrm{e}^{-04}$.

312 Juveniles and recruits did not show significant differences in terms of $H_{e}$ and $H_{o}(P$ values

313 associated with the permutation procedure: $\mathrm{P}_{\mathrm{Ho}}=0.65$ and $\mathrm{P}_{\mathrm{He}}=0.71$ ); while recruits showed a 314 significantly higher allelic richness than juveniles $\left(\mathrm{P}_{\mathrm{Ar}}=0.001\right)$.

\section{Relatedness}

A high degree of genetic relatedness among individuals was found. The mean observed relatedness was significantly different from the expected relatedness under panmixia (observed mean $\mathrm{rxy}=0.027$, resampled mean $\mathrm{rxy}=0.014, \mathrm{t}=1173, \mathrm{P}=0.001)$. Pairwise relatedness based on the Queller \& Goodnight, (1989) coefficient revealed that 25.98\% of the pairwise comparisons were involved in one or more parentage relationships, with $8.57 \%$ and $17.41 \%$ of individuals involved in a full-sib and half-sib relationship, respectively. These percentages were numerically similar considering the relatedness within the two temporal cohorts separately.

The percentage of individuals correctly assigned at the same tile where they were found by the individual assignments method using GENECLASS was around 50\%. The effective population size $(\mathrm{Ne})$ was estimated as 68.7 (95\% CI: 42.5-116.4) including all the individuals and as 32.5 for recruits (95\% CI: 20.6-57.8) and -1467.8 for juveniles $(95 \%$ CI: $87.1-\infty)$. The last negative value is expected when the population is sufficiently large that no notable linkage disequilibrium is induced through genetic drift (Waples \& Do, 2010).

\section{Spatial and temporal genetic structure}


332 No genetic structuring was observed between recruits and juveniles $\left(\mathrm{F}_{\mathrm{ST}}=0.008, \mathrm{P}=0.16\right)$. The

333 clustering method identified K = 2 gene pools based on Evanno's delta K statistic (Supplemental

334 Fig. S1, S2) but with high levels of admixture as many individuals could not be undoubtedly

335 assigned to either cluster. Nevertheless, an eastward genetic gradient of differentiation were

336 observed. Regarding the results from the DAPC analysis, the plot of BIC as a function of the

337 number of clusters K (ranging from 1 to 16) did not present a real minimum (Supplemental Fig.

338 S3). Nevertheless, when using tiles as groups, the DAPC was in agreement with the Structure

339 results (Fig. 6) with a higher genetic isolation of the titles T3 and T4 with all the other tiles.

340 Significantly positive kinship coefficients were detected between all the individuals within the

341 single tile $(\phi \mathrm{ij}=0.066, \mathrm{p}<0.001)$ indicating that individuals within tiles had a higher genetic

342 relatedness than random pairs of individuals. Within the cave, the autocorrelogram suggested an

343 estimated patch size of less than $40 \mathrm{~cm}$ (Fig. 7). The spatial autocorrelation between individuals

344 within each tile showed a significant positive value within a range from 3 to $10 \mathrm{~cm}$.

345

346

347

348

349

350

351

352

353

354

\section{Discussion}

In the present study the early life history traits of the Mediterranean red coral have been investigated using settlement tiles deployed inside a submarine cave. Size and genetic structures of recruits have been analysed. Two cohorts of red coral recruits were collected and they showed significant variability in space and time. No significant genetic structure was observed between the two cohorts, while settlers on the same tiles were highly related, suggesting that larval clouds recruiting nearby are sibs.

In summers 2010 and 2011 C. rubrum successfully recruited on artificial tiles inside the cave. The density of settlers $\left(26.57 \pm 29,92\right.$ individuals $\left./ 400 \mathrm{~cm}^{2}\right)$ was higher compared to values found 
355 by Bramanti et al., (2014) in Cap de Creus marine reserve (Costa Brava, Spain: 42²9.21' N;

356

357 358 $03^{\circ} 30.18^{\prime} \mathrm{E}$, Spain, $5.6 \pm 2.8$ individuals $/ 400 \mathrm{~cm}^{2}$ ) and in Portofino (Eastern Ligurian Sea, Italy: $44^{\circ} 18.18^{\prime} \mathrm{N} ; 09^{\circ} 12.83^{\prime} \mathrm{E}$, Italy. $17.5 \pm 4.7$ individuals $/ 400 \mathrm{~cm}^{2}$ ). While adult colonies dwells on the ceiling and on the walls of the cave, in the current study settlers' density significantly differed between these two habitats, with higher values on the tiles located on the ceiling of the cave. The only three tiles (T1, T13, and T14) where no recruitment was recorded were positioned on the walls of the cave. The causes of these differences are not fully understood yet, but they could be related to several factors. Both larval behaviour and habitat constraints could influence the higher recruitment density observed on the ceiling. Even if C. rubrum larvae could survive at least 16 days (potentially up to 42 days) in the plankton (Martínez-Quintana et al., 2014), inside caves and/or overhangs they probably are trapped by the ceiling due to their negative geotaxis (Weinberg, 1979; Martínez-Quintana et al., 2014). Sediment deposition is a limiting factor for red coral recruitment, and observations made by Virgilio, Airoldi \& Abbiati, (2006) showed that a thin coat of sediment covering vertical surfaces affects colony densities. These findings suggest that red coral populations dwelling in crevices and caves are more resilient due to enhanced recruitment rates, while populations living on cliffs and on rocky bottoms, which are the most currently exploited, might be endangered due to recruitment limitation.

Due to the difficulties in identifying tiny individuals (Bramanti, Magagnini \& Santangelo, 2003), only a few studies have investigated the early life stage of this species (Garrabou \& Harmelin, 2002; Bramanti et al., 2005, 2007). By using settlement tiles, it was possible to discriminate two early life stages of C. rubrum: recruits and juveniles. Significant variation in the abundance of recruits and juveniles were observed, suggesting both an inter-annual variability in larval supply and/or post-settlement mortality. However, it is not easy to disentangle these two processes, and 
378 this was not in the scope of this study. Concerning post-settlement processes, they include the 379 intra- and inter-specific interactions mediated by chemical cues, food limitation, local water 380 flow, predation and competition for space (Fraschetti et al., 2002). Competition for space, together with grazing intensity, is known to produce variations in coral recruitment at this spatial scale (Babcock \& Mundy, 1996). All these processes, and their interactions, contribute to the high mortality rates in gorgonian recruits (Caley et al., 1996; Perkol-Finkel et al., 2008), including C. rubrum (Garrabou \& Harmelin, 2002; Bramanti, Magagnini \& Santangelo, 2003).

The number of polyps per individuals was consistent to Bramanti et al., (2005), with a higher number of polyps in juveniles compared to recruits, and a significant correlation between number of polyps and height in the juveniles. Moreover, individuals settling on tiles showed a considerable variability in diameter and height, suggesting that growth rate in early red coral stages may be extremely variable and possibly much higher than the growth rates estimated from adult colonies $(0.89 \mathrm{~mm}$ /year between the first and second years, Bramanti et al. 2005; but see Table S2 in Cerrano et al., 2013). Considering that in this study the age of colonies on tiles was 20 months (for the juveniles), an average annual growth rate in diameter of $1.48 \mathrm{~mm} / \mathrm{year}$ for juveniles has been estimated. These results support the high variation in colony growth rates among geographic regions and in the early stages of colony life (Santangelo et al., 2012; Cerrano et al., 2013).

An important finding of the genetic characterization of settlers within the Colombara cave is that several identical multi locus genotypes (MLGs) were shared by recruits and juveniles. However, up to now, no evidence of asexual reproduction and/or polyp bail-out were reported in Corallium rubrum. The most likely explanation for the presence of identical MLGs is that, due to the low level of genetic variability of the species, these individuals are sibs. 
401 The low levels of observed heterozygosity (mean Ho $=0.29 \pm 0,20$ ) compared to that previously 402 pointed out in natural populations (Mean $\mathrm{Ho}=0.32 \pm 0.04$, Costantini, Fauvelot \& Abbiati, 403 2007; meand Ho $=0.5$, Ledoux et al., 2010a), could be due to the small population size.

However, this hypothesis seems unlikely considering the high density of settlers on the tiles, and

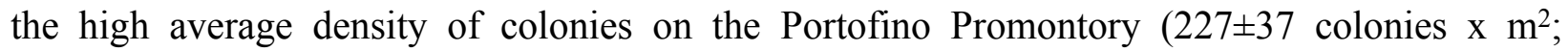
Bavestrello et al., 2015), including the Colombara cave (Cerrano C. pers. obs.). The observed genetic variability suggests high genetic drift acting within the cave. In fact, a correlation between low genetic variability and low effective population size was already observed in Corallium rubrum (Ledoux et al., 2015) confirming that genetic drift might be relevant in this species (Costantini, Fauvelot \& Abbiati, 2007; Ledoux et al., 2010a). Moreover, as tested by Costantini, Fauvelot \& Abbiati, (2007) the presence of spatial and/or temporal mixing of differentiated gene pools (e.g. Wahlund effect) could explain the previous observed high levels of heterozygosity.

The significant deviations from Hardy-Weinberg equilibrium, emphasized by the high positive $\mathrm{F}_{\mathrm{IS}}$ estimates, it is unlikely to be related to null alleles. Occurrence of null alleles in red coral populations has been previously reported (Costantini, Fauvelot \& Abbiati, 2007), however, in this study their frequency is low and it should not affect observed heterozygosity. High inbreeding rates (e.g. mating between relatives) are a more likely explanation for the $\mathrm{F}_{\mathrm{IS}}$ values. This phenomenon was already observed in Corallium rubrum (Costantini, Fauvelot \& Abbiati, 2007). This hypothesis is also supported by the occurrence of sibs on a single tile, suggesting limited larval dispersal and/or collective dispersal (Broquet \& Yearsley, 2012). Settlers' consanguinity could be explained by other factors (e.g., asynchrony of reproduction events, gametes' behaviour, uneven sex ratio and clonality). Little is known about red coral 
424 gametes behaviour (Santangelo et al., 2003) but other possible explanations seem unlikely. In 425 fact, in Corallium rubrum the sex ratio is balanced (Tsounis et al., 2006; Bramanti et al., 2014;

426 Santangelo et al., 2015), reproduction is not completely synchronous but occurs within a discrete 427 time-interval in summer (Santangelo et al., 2003), and up to now clonality (asexual reproduction)

was not observed. Moreover, no genetic structure was observed between the two analysed cohorts of settlers. All these findings, including the high relatedness among settlers (full and half-sib relationship), suggest that in both cohorts larval supply was provided by a limited number of genetically similar adult colonies (or progenitors). Fine spatial scale genetic structure is a common feature of gorgonians (Brazeau, Sammarco \& Atchison, 2011), including red coral (Costantini, Fauvelot \& Abbiati, 2007; Ledoux et al., 2010a). In the Colombara cave a population patch size of about $8 \mathrm{~cm}$ was detected, of the same range observed by Ledoux et al. (2010a) in a Mediterranean marine cave close to Marseilles (20-30 cm). These high SGS, together with the low genetic variability and the high inbreeding rate, in a close environment as a marine cave, could enhance local adaptation. However, further reduction of genetic diversity, and hence reduction of population size due to, for example, global changes (e.g. thermal anomalies, acidification), could lead to overcoming the 'inbreeding threshold,' resulting in reductions of both fitness and of the risk of local extinction (Frankham, 1995).

\section{Conclusion}

The present study provides new insight concerning recruitment processes in red coral populations using a submarine cave as an experimental mesocosm. The main outcome of the study is that C. rubrum individuals settling in the Colombara cave are highly related at very small spatial scales, and that most larvae recruiting nearby are sibs. Evidence of the processes explaining this pattern cannot be provided, however, self-recruitment and the presence of clouds 
447 of larvae that settle all together could be possible explanations. Parentage analyses between adult

448 individuals, both inside and outside the cave, and the recruits would help to disentangle the two

449 processes. Understanding processes acting in the early life history of a species is a challenging

450 but crucial task, with major implications for conservation. In fact, these processes drive the

451 population structure and dynamic of the species, and are essential for the resistance and

452 resilience of populations.

453

454

455

456

457

458

459

460

461

462

463

464

465

466

467

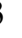

\section{Acknowledgements}

We would like to thank the director of the Portofino MPA Dr. Giorgio Fanciulli, and the Università Politecnica delle Marche for the authorization of the field experiments. We thank Adriana Villamor for her advice during the lab work; Massimo Ponti for his help in the imaging data analysis, Marco Palma and Ubaldo Pantaleo for field assistance and Paolo Mancuso for his great drawing capacity. Part of this research has been performed in the frame of the Mesomed project in collaboration with Portofino Divers. This work is part of the PRIN 2010-2011 (prot. 2010Z8HJ5M), and PRIN 2015 (prot. 2015J922E4) projects by the Italian Ministry of Education, University and Research.

\section{References}

Babcock R, Mundy C. 1996. Coral recruitment: consequences of settlement choice for early growth and survivorship in two scleractinians. Journal of Experimental Marine Biology and Ecology 206:179-201. DOI: https://doi.org/10.1016/S0022-0981(96)02622-6 
Bavestrello G, Bianchi C, Calcinai B, Cattaneo-Vietti R, Cerrano C, Morri C, Puce S, Sara M. 2000. Bio-mineralogy as a structuring factor for marine epibenthic communities. Marine Ecology Progress Series 193:241-249. DOI:10.3354/meps193241

Bavestrello G, Bo M, Bertolino M, Betti F, Cattaneo-vietti R. 2015. Long-term comparison of structure and dynamics of the red coral metapopulation of the Portofino Promontory (Ligurian Sea ): a case-study for a Marine Protected Area in the Mediterranean Sea. Marine Ecology 36:1354-1363. DOI: 10.1111/maec.12235.

Belkhir K, Borsa P, Chikhi L, Raufaste N, Bonhomme F. 2000. GENETIX 4.05, Logiciel sous Windows pour la Génétique des Populations. Laboratoire Genome et Populations,

Universite de Montpellier, Montpellier.

Belkhir K, Castric V, Bonhomme F. 2002. Identix, a software to test for relatedness in a population using permutation methods. Molecular Ecology Notes 2:611-614. DOI: 10.1046/j.1471-8286.2002.00273.x.

Benjamini Y, Hochberg Y. 1995. Controlling the False Discovery Rate: a practical and powerful approach to multiple esting. Journal of the Royal Statistical Society. Series B (Methodological) 57:289-300. DOI: doi:10.2307/2346101.

Bramanti L, Edmunds P. 2016. Density-dependent recruitment mediates coral population dynamics on a coral reef. Coral Reefs 35:543-553. DOI: 10.1007/s00338-016-1413-4.

Bramanti L, Magagnini G, De Maio L, Santangelo G. 2005. Recruitment, early survival and growth of the Mediterranean red coral Corallium rubrum (L 1758), a 4-year study. Journal of Experimental Marine Biology and Ecology 314:69-78. DOI: 10.1016/j.jembe.2004.08.029.

Bramanti L, Magagnini G, Santangelo G. 2003. Settlement and recruitment: the first stages in the 
life cycle of two epibenthic suspension feeders (Corallium rubrum and Anomia ephippium). Italian Journal of Zoology 67:295-299. DOI: https://doi.org/10.1080/11250000309356512.

Bramanti L, Movilla J, Guron M, Calvo E, Gori A, Dominguez-Carrió C, Grinyó J, Lopez-Sanz A, Martinez-Quintana A, Pelejero C, Ziveri P, Rossi S. 2013. Detrimental effects of ocean acidification on the economically important Mediterranean red coral (Corallium rubrum). Global Change Biology 19:1897-1908. DOI: 10.1111/gcb.12171.

Bramanti L, Rossi S, Tsounis G, Gili JM, Santangelo G. 2007. Settlement and early survival of red coral on artificial substrates in different geographic areas: some clues for demography and restoration. Hydrobiologia 580:219-224. DOI: 10.1007/s10750-006-0452-1.

Bramanti L, Vielmini I, Rossi S, Tsounis G, Iannelli M, Cattaneo-Vietti R, Priori C, Santangelo G. 2014. Demographic parameters of two populations of red coral (Corallium rubrum L. 1758) in the North Western Mediterranean. Marine Biology 161:1015-1026. DOI: $10.1007 / \mathrm{s} 00227-013-2383-5$.

Brazeau D, Sammarco P, Atchison A. 2011. Micro-scale genetic heterogeneity and structure in coral recruitment: fine-scale patchiness. Aquatic Biology 12:55-67. DOI: 10.3354/ab00313.

Broquet T, Yearsley JM. 2012. Genetic drift and collective dispersal can result in chaotic genetic patchiness. Evolution 67:1660-1675. DOI: 10.5061/dryad.612g8.

Caley J, Carr M, Hixon M, Hughes T, Jones G, Menge B. 1996. Recruitment and the local dynamics of open marine populations. Annual Revue in Ecology and Systematic 27:477500. DOI: https://doi.org/10.1146/annurev.ecolsys.27.1.477.

Cattaneo-Vietti R, Bavestrello G, Senes L. 1993. Red coral from the Portofino Promontory (Ligurian Sea). In: Cicogna F, Cattaneo-Vietti R (eds) Red coral in the Mediterranean Sea: art, history and science. Ministerio delle Risorse Agricole, Ali-mentari e Forestali, Roma, 
514

515

516

517

518

519

520

521

522

523

524

525

526

527

pp 109-130

Cerrano C, Bavestrello G, Bianchi C. 2000. A catastrophic mass-mortality episode of gorgonians and other organisms in the Ligurian Sea (North-western Mediterranean), summer 1999. Ecology Letters 3:284-293. DOI: DOI: 10.1046/j.1461-0248.2000.00152.x.

Cerrano C, Cardini U, Bianchelli S, Corinaldesi C, Pusceddu A, Danovaro R. 2013. Red coral extinction risk enhanced by ocean acidification. Scientific Reports 3:284-293 DOI: $10.1038 /$ srep01457.

Chapuis M, Estoup A. 2007. Microsatellite null alleles and estimation of population differentiation. Molecular Biology and Evolution 24:621-631. DOI: 10.1093/molbev/msl191.

Clarke K, Gorley R. 2006. RIMER v6: User Manual/Tutorial. Plymouth: PRIMER-E. :192.

Costantini F, Abbiati M. 2006. Development of microsatellite markers for the Mediterranean gorgonian coral Corallium rubrum. Molecular Ecology Notes 6:521-523. DOI: 10.1111/j.1471-8286.2006.01305.x.

Costantini F, Fauvelot C, Abbiati M. 2007. Fine-scale genetic structuring in Corallium rubrum: evidence of inbreeding and limited effective larval dispersal. Marine Ecology Progress Series 340:109-119. DOI: 10.3354/meps340109.

Dempster A, Laird N, Rubin D. 1977. Maximum likelihood from incomplete data via the EM algorithm. Journal of the Royal Statistical Society 39:1-38.

Eldon B, Riquet F, Yearsley J, Jollivet D, Broquet T. 2016. Current hypotheses to explain genetic chaos under the sea. Current Zoology 62:1-54. DOI: 10.1093/cz/zow094.

Falush D, Stephens M, Pritchard J. 2007. Inference of population structure using multilocus genotype data: dominant markers and null alleles. Molecular Ecology Notes 7:574-578. 
DOI: 10.1111/j.1471-8286.2007.01758.x.

Frankham R. 1995. Inbreeding and extinction: a threshold effect. Conservation Biology 9:792799. DOI: $10.1046 / j .1523-1739.1995 .09040792 . x$.

Fraschetti S, Giangrande A, Terlizzi A, Boero F. 2002. Pre- and post-settlement events in benthic community dynamics. Oceanologica Acta 25:285-295. DOI: 10.1016/S03991784(02)01194-5.

Garrabou J, Harmelin J. 2002. A 20-year study on life-history traits of a harvested long-lived temperate coral in the NW Mediterranean: insights into conservation and management needs. Journal of Animal Ecology 71:966-978. DOI: 10.1046/j.1365-2656.2002.00661.x.

Gerovasileiou V, Voultsiadou E. 2012. Marine caves of the Mediterranean Sea: a sponge biodiversity reservoir within a biodiversity hotspot. PloS one 7:e39873. DOI: 10.1371/journal.pone.0039873.

Goudet J. 2001. FSTAT, a program to estimate and test gene diversi- ties and fixation indices (version 2.9.3). Available from http://ww w.unil.ch/izea/softwares/fstat.html. Updated from Goudet (1995).

Goudet J, Raymond M, De-Meeus T, Rousset F. 1996. Testing differentiation in diploid populations. Genetics 144:1933-1940.

Green DH, Edmunds PJ. 2011. Spatio-temporal variability of coral recruitment on shallow reefs in St. John, US Virgin Islands. Journal of Experimental Marine Biology and Ecology 397:220-229. DOI: 10.1016/j.jembe.2010.12.004.

Guizien K, Belharet M, Guarini J, Marsaleix P. 2012. Using larval dispersal simulations for marine protected area design: application to the Gulf of Lions (northwest Mediterranean). Limnology and Oceanography 57:1099-1112. DOI: 10.4319/lo.2012.57.4.1099. 
560 Guizien K, Brochier T, Duche^ne JC, Koh BS, Marsaleix P. 2006. Dispersal of Owenia

561 fusiformis larvae by wind-driven currents: turbulence, swimming behaviour and mortality in

562 a threedimensional stochastic model. Marine Ecology Progress Series 311:47-66. DOI:

$563 \quad$ DOI10.3354/meps311047.

564 Hardy OJ. 1999. Isolation by distance in a continuous population: reconciliation between spatial 565 autocorrelation analysis and population genetics models. Heredity 83:145. DOI: 
of allelic richness. Molecular Ecology Notes 5:187-189.

Kendall M, Stewart A. 1977. The advanced theory of statistics. Vol. 1. New York: Macmillan.

Kopelman NM, Mayzel J, Jakobsson M, Rosenberg NA, Mayrose I. 2015. CLUMPAK: a program for identifying clustering modes and packaging population structure inferences across K. Molecular Ecology Resources 15:1179-1191. DOI: 10.1111/1755-0998.12387.

Laborel J, Vacelet J. 1961. Répartition bionomique du Corallium rubrum LMCK dans les grottes et falaises sous-marines. Rapports et Proces-Verbaux des Réunions de la Commission Internationale pour l'Exploration Scientifique de la Mer Méditerranée 16:464-469.

Ledoux J-B, Aurelle D, Bensoussan N, Marschal C, Féral J-P, Garrabou J. 2015. Potential for adaptive evolution at species range margins: contrasting interactions between red coral populations and their environment in a changing ocean. Ecology and Evolution 5:11781192. DOI: DOI: 10.1002/ece3.1324.

Ledoux J-B, Garrabou J, Bianchimani O, Drap P, Féral J-P. Aurelle D. 2010a. Fine-scale genetic structure and inferences on population biology in the threatened Mediterranean red coral, Corallium rubrum. Molecular Ecology 19:4204-4216. DOI: 10.1111/j.1365294X.2010.04814.x.

Ledoux J-B, Mokhtar-Jamaï K, Roby C, Féral J-P, Garrabou J, Aurelle D. 2010b. Genetic survey of shallow populations of the Mediterranean red coral [Corallium rubrum (Linnaeus, 1758)]: new insights into evolutionary processes shaping nuclear diversity and implications for conservation. Molecular Ecology 19:675-90. DOI: 10.1111/j.1365-294X.2009.04516.x.

Lindsay SM, Wethey DS, Woodin SA. 1997. Modeling interactions of browsing predation, infaunal activity, and recruitment in marine soft-sediment habitats. The American Naturalist 148: 684-699. 
Loiselle BA, Sork VL, Nason J, Graham C. 1995. Spatial genetic structure of a tropical understory shrub, Psychotria officinalis (Rubiaceae). American Journal of Botany 82:1420. DOI: $10.2307 / 2445869$.

Martínez-Quintana A, Bramanti L, Viladrich N, Rossi S, Guizien K. 2014. Quantification of larval traits driving connectivity: the case of Corallium rubrum (L. 1758). Marine Biology 162:309-318. DOI: 10.1007/s00227-014-2599-z.

Morri C, Bianchi CN, Damiani V, Peirano A, Romeo G, Tunesi L. 1986. L'ambiente marino tra Punta della Chiappa e Sestri Levante (Mar Ligure): profilo ecotipologico e proposta di carta bionómica. Boll. Mus. Ist. Biol. Univ. Genova 52:213-231.

Nei M. 1973. Analysis of gene diversity in subdivided populations. Proceedings of the National Academy of Sciences 70:3321-3323. DOI: 10.1073/pnas.70.12.3321.

Van Oosterhout C, Hutchinson WF, Wills DPM, Shipley P. 2004. Micro-checker: software for identifying and correcting genotyping errors in microsatellite data. Molecular Ecology Notes 4:535-538. DOI: 10.1111/j.1471-8286.2004.00684.x.

Peakall R, Smouse PE. 2006. Genalex 6: genetic analysis in Excel. Population genetic software for teaching and research. Molecular Ecology Notes 6:288-295. DOI: 10.1111/j.14718286.2005.01155.x.

Perkol-Finkel S, Zilman G, Sella I, Miloh T, Benayahu Y. 2008. Floating and fixed artificial habitats: Spatial and temporal patterns of benthic communities in a coral reef environment. Estuarine, Coastal and Shelf Science 77:491-500. DOI: 10.1016/j.ecss.2007.10.005.

Pineda J, Hare JJ, Sponaungle S, Sponaugle S. 2007. Larval transport and dispersal in the coastal ocean and consequences for population connectivity. Oceanography 20:22-39. DOI: 10.5670/oceanog.2007.27. 
629 Piry S, Alapetite A, Cornuet J-M, Paetkau D, Baudouin L, Estoup A. 2004. GENECLASS2: a

630 software for genetic assignment and first-generation migrant detection. The Journal of

631 heredity 95:536-9. DOI: 10.1093/jhered/esh074.

632 Pritchard J, Matthew S, Donnelly P. 2000. Inference of population structure using multilocus

633 genotype data. Genetics 155:945-959.

634 Queller D, Goodnight K. 1989. Estimating relatedness using genetic markers. Evolution 43:258$635 \quad 275$.

636

637

638

Rastorgueff PA, Bellan-Santini D, Bianchi CN, Bussotti S, Chevaldonné P, Guidetti P, Harmelin JG, Montefalcone M, Morri C, Perez T, Ruitton S, Vacelet J. PS. 2015. An ecosystem-based approach to evaluate the ecological quality of Mediterranean undersea caves. Ecological Indicators 54:137-152.

Raymond M, Rousset F. 1995. An exact test for population differentiation. Evolution 49:12801283. DOI: $10.2307 / 2410454$.

Sanford E. Kelly MW. 2011. Local adaptation in marine invertebrates. Annual Review of Marine Science 3:509-535. DOI: 10.1146/annurev-marine-120709-142756.

Santangelo G, Bramanti L, Rossi S, Tsounis G, Vielmini I, Lott C, Gili JM. 2012. Patterns of variation in recruitment and post-recruitment processes of the Mediterranean precious gorgonian coral Corallium rubrum. Journal of Experimental Marine Biology and Ecology 411:7-13. DOI: 10.1016/j.jembe.2011.10.030.

Santangelo G, Carletti E, Maggi E, Bramanti L. 2003. Reproduction and population sexual structure of the overexploited Mediterranean red coral Corallium rubrum. Marine Ecology Progress Series 248:99-108. DOI: 10.3354/meps248099.

Santangelo G, Bramanti L, Rossi S, Tsounis G, Vielmini I, Lott C, Gili JM. 2012. Patterns of 
652

653

654

655

656

657

658

659

660

661

662

663

664

665

666

667

668

669

670

671

672

673

674

variation in recruitment and post-recruitment processes of the Mediterranean precious gorgonian coral Corallium rubrum. Journal of Experimental Marine Biology and Ecology 411:7-13. DOI: 10.1016/j.jembe.2011.10.030.

Santangelo G, Cupido R, Cocito S, Bramanti L, Priori C, Erra F, Iannelli M. 2015. Effects of increased mortality on gorgonian corals (Cnidaria, Octocorallia): different demographic features may lead affected populations to unexpected recovery and new equilibrium points. Hydrobiologia 759:171-187. DOI: 10.1007/s10750-015-2241-1.

Smilansky V, Lasker HR. 2014. Fine-scale genetic structure in the surface brooding Caribbean octocoral, Antillogorgia elisabethae. Marine Biology 161:853-861. DOI: 10.1007/s00227013-2385-3.

Core Team (2012). R: A language and environment for statistical computing. R Foundation for statistical computing, Vienna, Austria. URL http://www.R-project.org/.

Torda G, Lundgren P, Willis BL, van Oppen MJH. 2013. Genetic assignment of recruits reveals short- and long-distance larval dispersal in Pocillopora damicornis on the Great Barrier Reef. Molecular ecology 22:5821-34. DOI: 10.1111/mec.12539.

Tsounis G, Rossi S, Aranguren M, Gili J-M, Arntz W. 2006. Effects of spatial variability and colony size on the reproductive output and gonadal development cycle of the Mediterranean red coral (Corallium rubrum L.). Marine Biology 148:513-527. DOI: 10.1007/s00227-0050100-8.

Tsounis G, Rossi S, Bramanti L, Santangelo G. 2013. Management hurdles for sustainable harvesting of Corallium rubrum. Marine Policy 39:361-364. DOI: 10.1016/j.marpol.2012.12.010.

Vekemans X, Hardy OJ. 2004. New insights from fine-scale spatial genetic structure analyses in 
675 plant populations. Molecular Ecology 13:921-935. DOI: 10.1046/j.1365676 294X.2004.02076.x.

677 Virgilio M, Airoldi L, Abbiati M. 2006. Spatial and temporal variations of assemblages in a 678 Mediterranean coralligenous reef and relationships with surface orientation. Coral Reefs 25:265-272. DOI: 10.1007/s00338-006-0100-2.

680

681 682 683 684 685 686 687 688 689 690 691
Waples R. 2006. A bias correction for estimates of effective population size based on linkage disequilibrium at unlinked gene loci. Conservation Genetics 7:167-184.

Waples RS, Do CHI. 2008. LDNE: a program for estimating effective population size from data on linkage disequilibrium. Molecular Ecology Resources 8:753-756.

Waples RS, Do C. 2010. Linkage disequilibrium estimates of contemporary Ne using highly variable genetic markers: A largely untapped resource for applied conservation and evolution. Evolutionary Applications 3:244-262.

Weinberg S. 1979. The light-dependent behaiviour of planulae larvae of Eunicella singularis and Corallium rubrum and its implications for for octocoral ecology. Bijds. Dijerkd 49:16-30.

Weir B, Cockerham C. 1984. Estimating F-statistics for the analysis of population structure. Evolution 38:1358-1370. DOI: 10.2307/2408641. 


\section{Figure 1 (on next page)}

Maps of sampling location and scheme of the sampling design
A) Overview of the geographic location of the Colombara cave. B) zoom of the Portofino promontory where the cave is located. C) front of the cave and scheme of the tiles deployed. D) profile of the cave. White rectangles represent the tiles. Rectangles without number represent the lost tiles. Drawing made by Mancuso FP. 
A

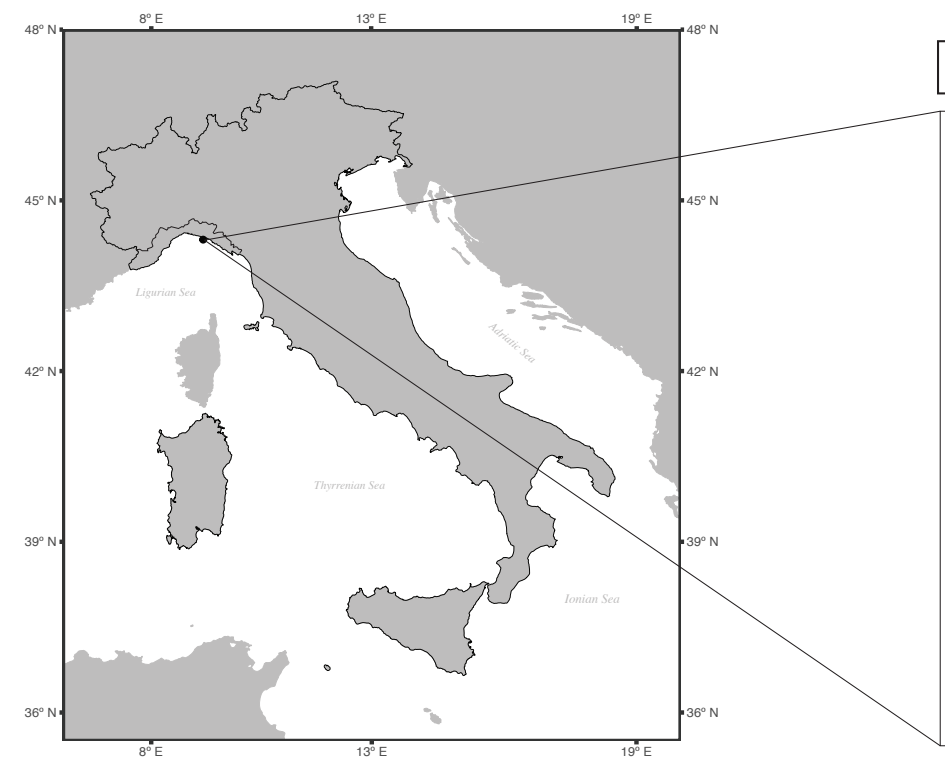

B
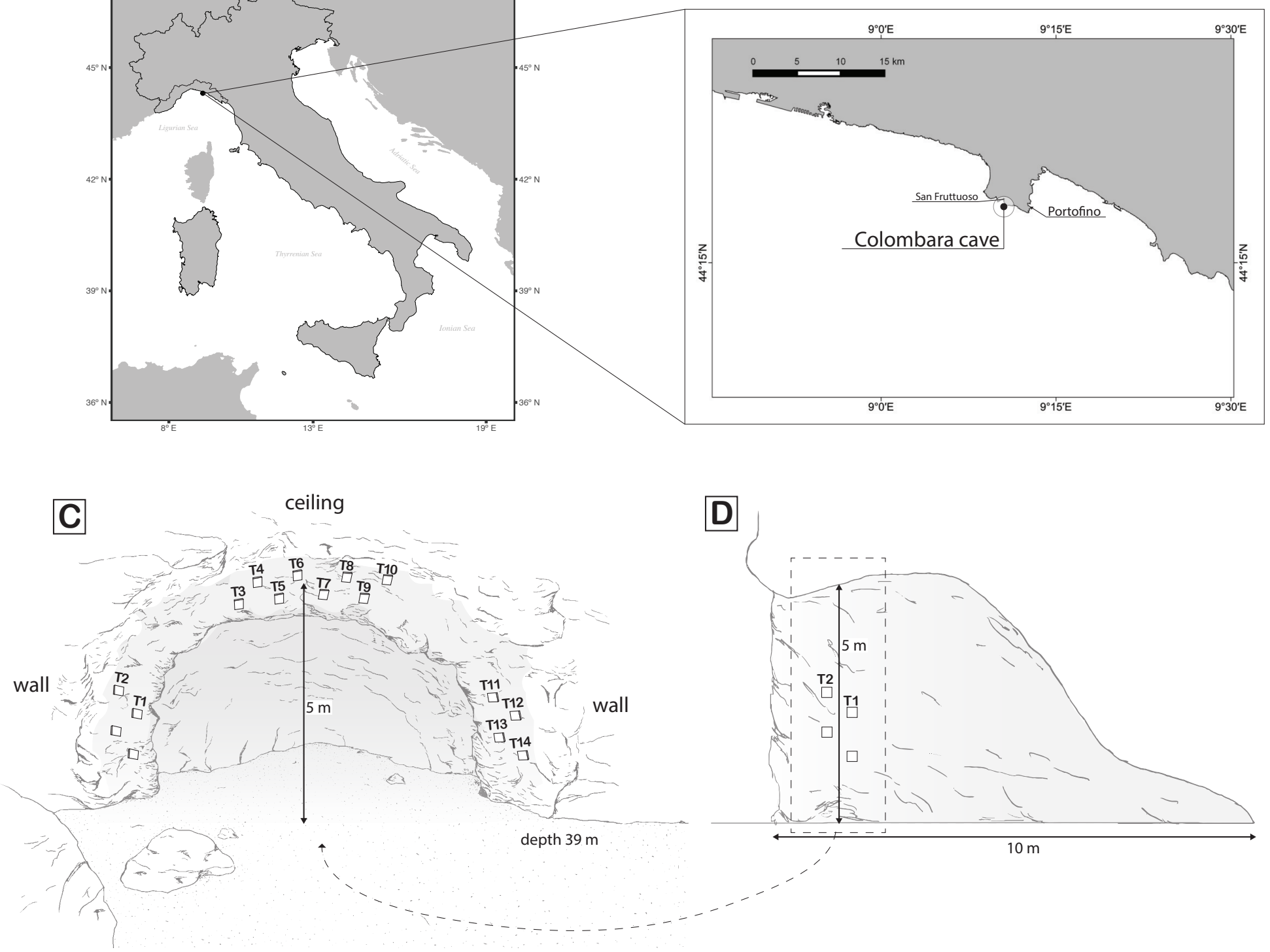
Figure 2

Example of a PVC tile recovered from the Colombara cave after two years.

(A) Tile T7, (B) zoom of a recruit, (C) a juvenile, (D) a recruit probably derived by two merged planulae.

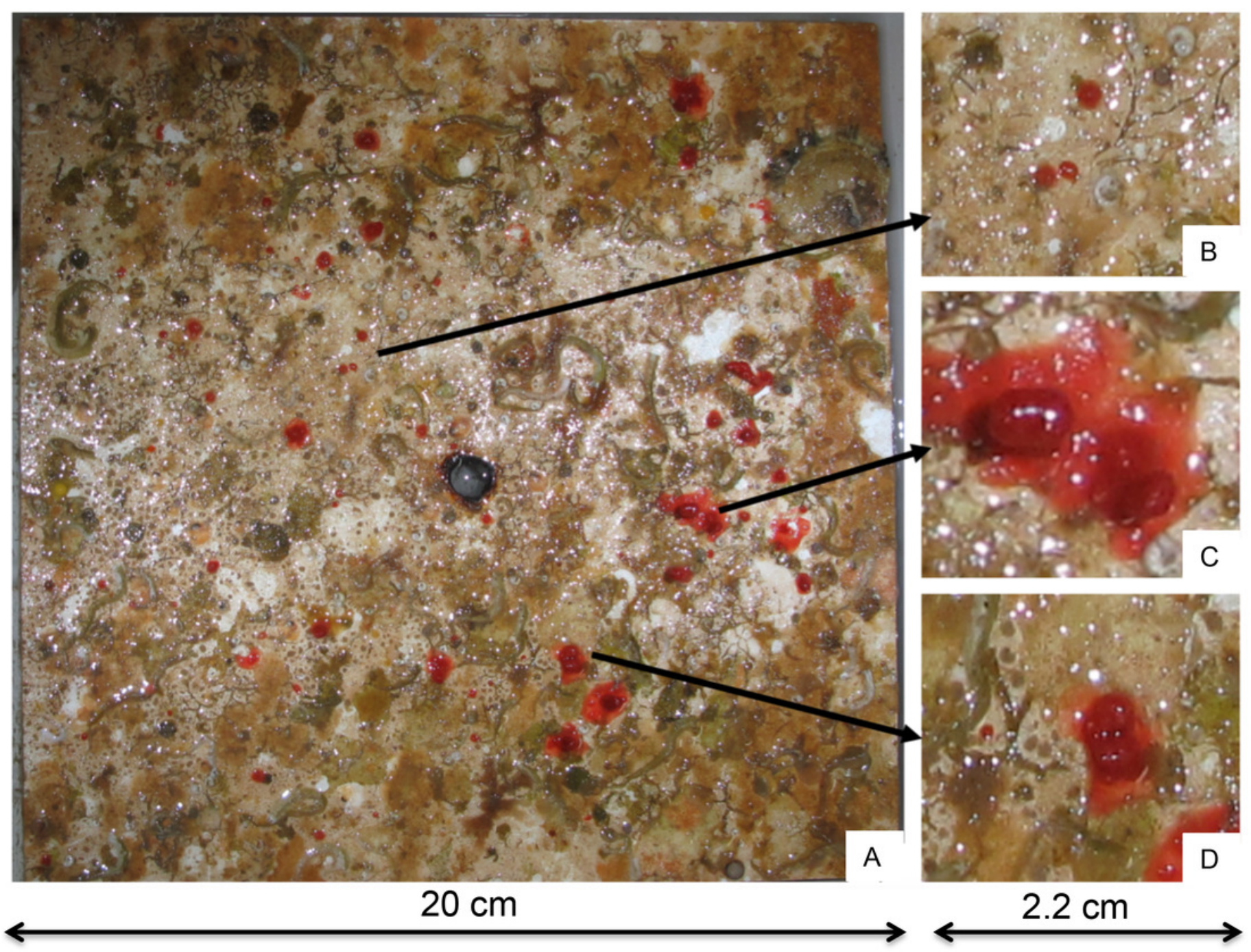


Figure 3 (on next page)

Number of settlers on the 14 tiles deployed in the Colombara cave. 


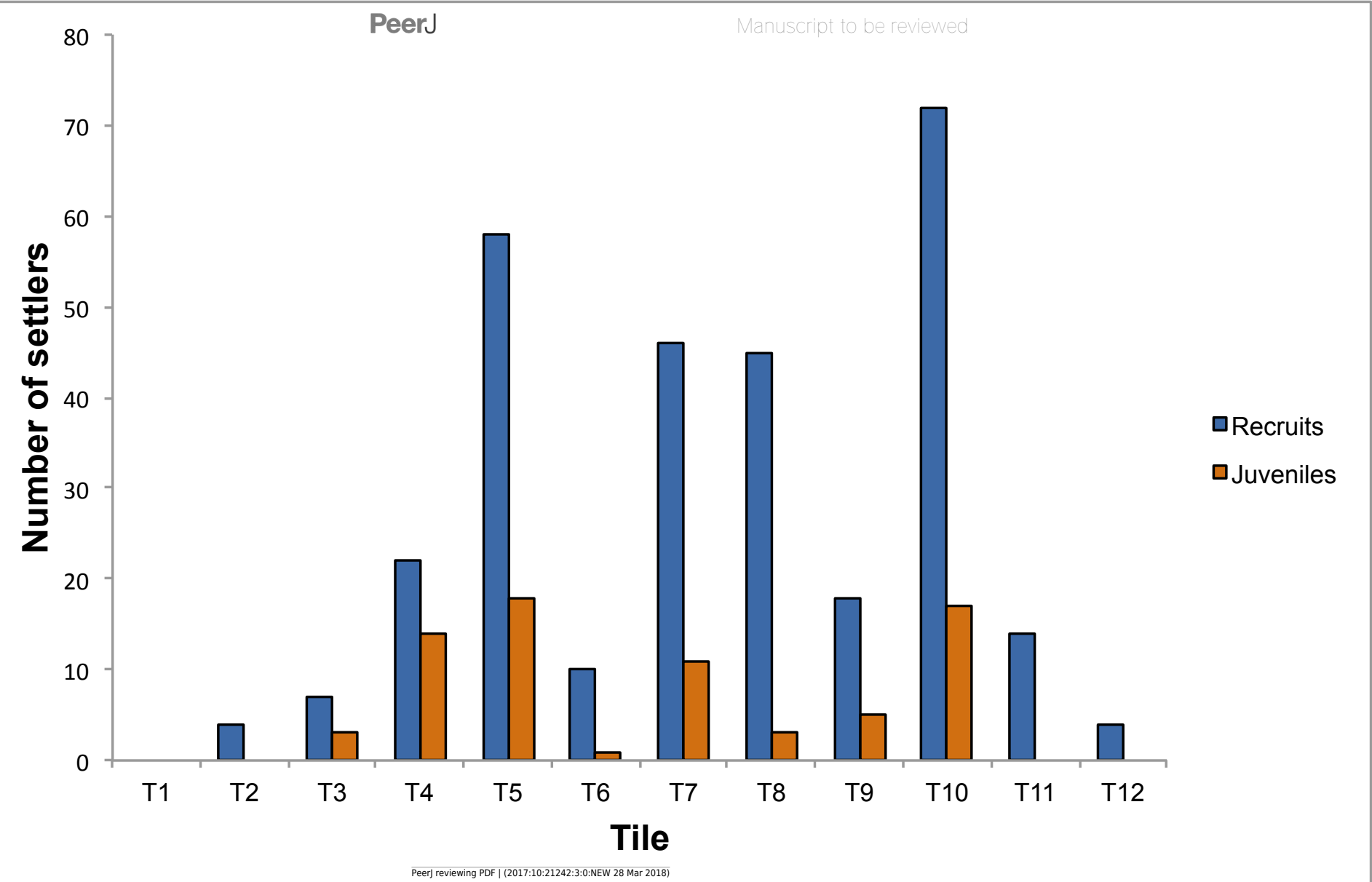


Figure 4 (on next page)

Distribution of red coral recruits.

A) Diameter classes, B) number of polyp's classes, C) relationship between number of polyps and diameter. r.: Pearson coefficient. 

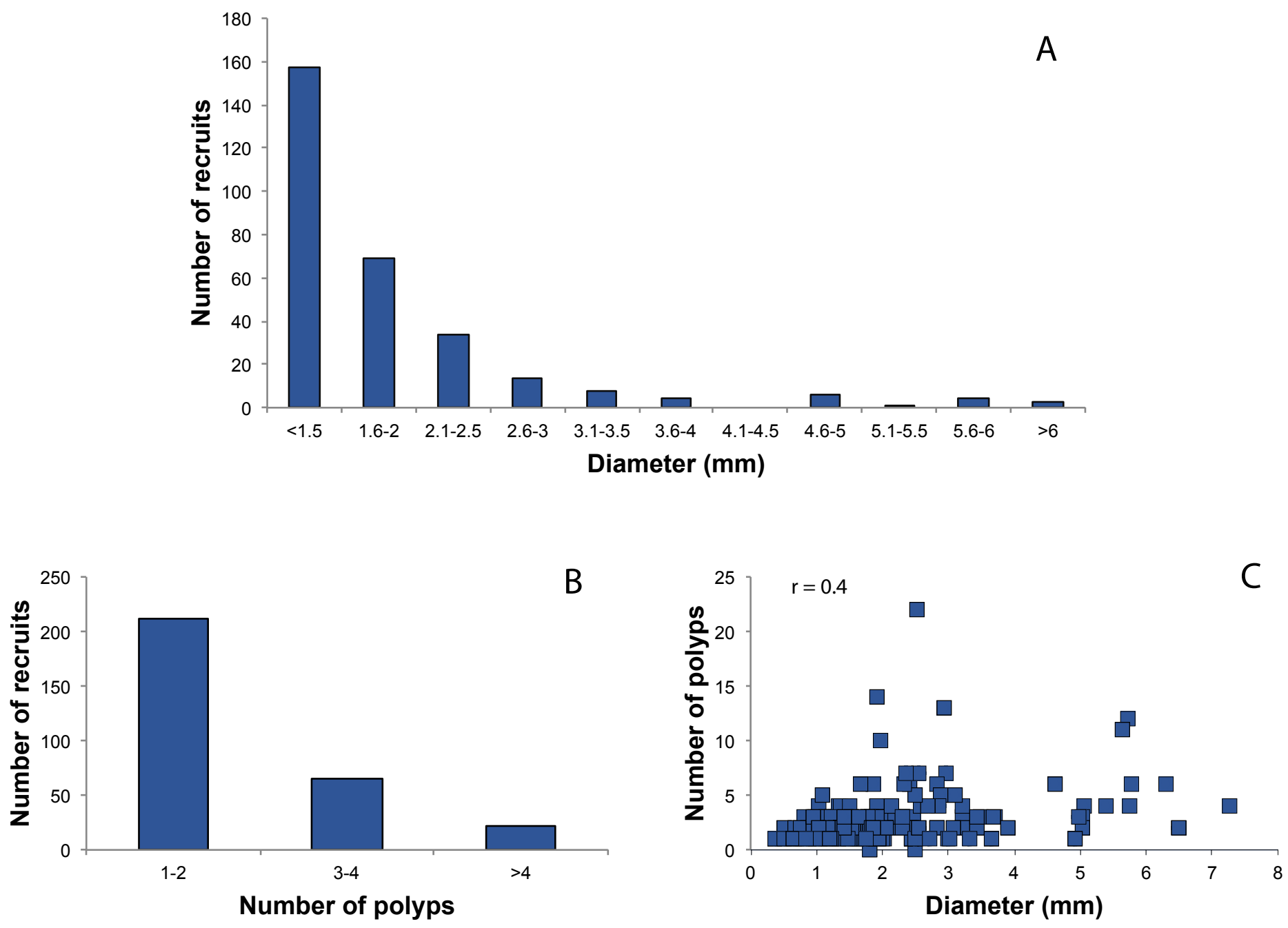
Figure $\mathbf{5}$ (on next page)

Distribution of red coral juveniles.

A) Diameter classes, C) number of polyps classes, E) height classes. Relationship between: B) number of polyps and diameter, D) number of polyps and height, F) height and diameter. r.: Pearson coefficient. 

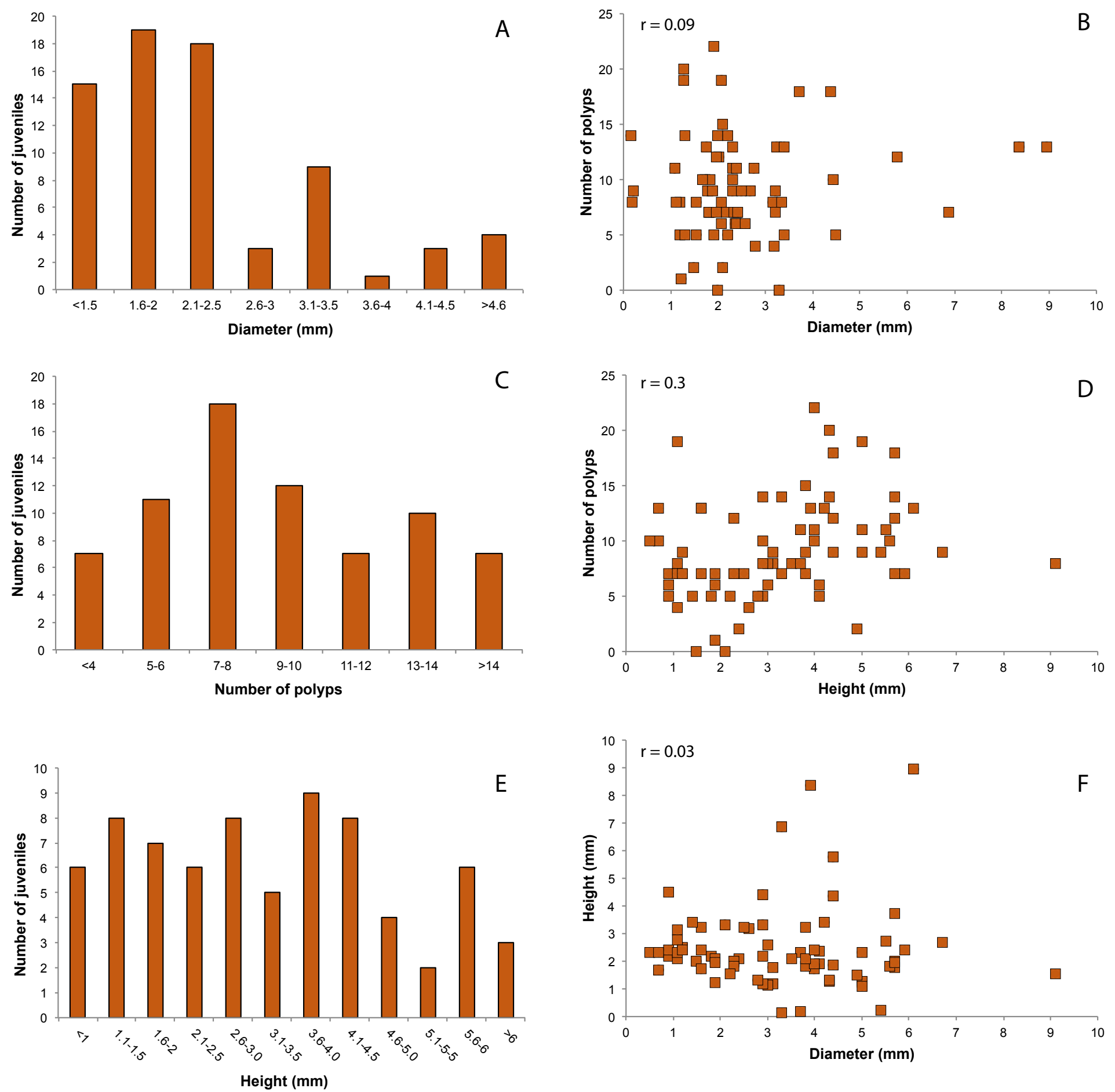


\section{Figure 6 (on next page)}

Scatterplot of the Discriminant analysis of principal components (DAPC) of the settlers found in the tiles deployed in ceiling of the Colombara cave. 


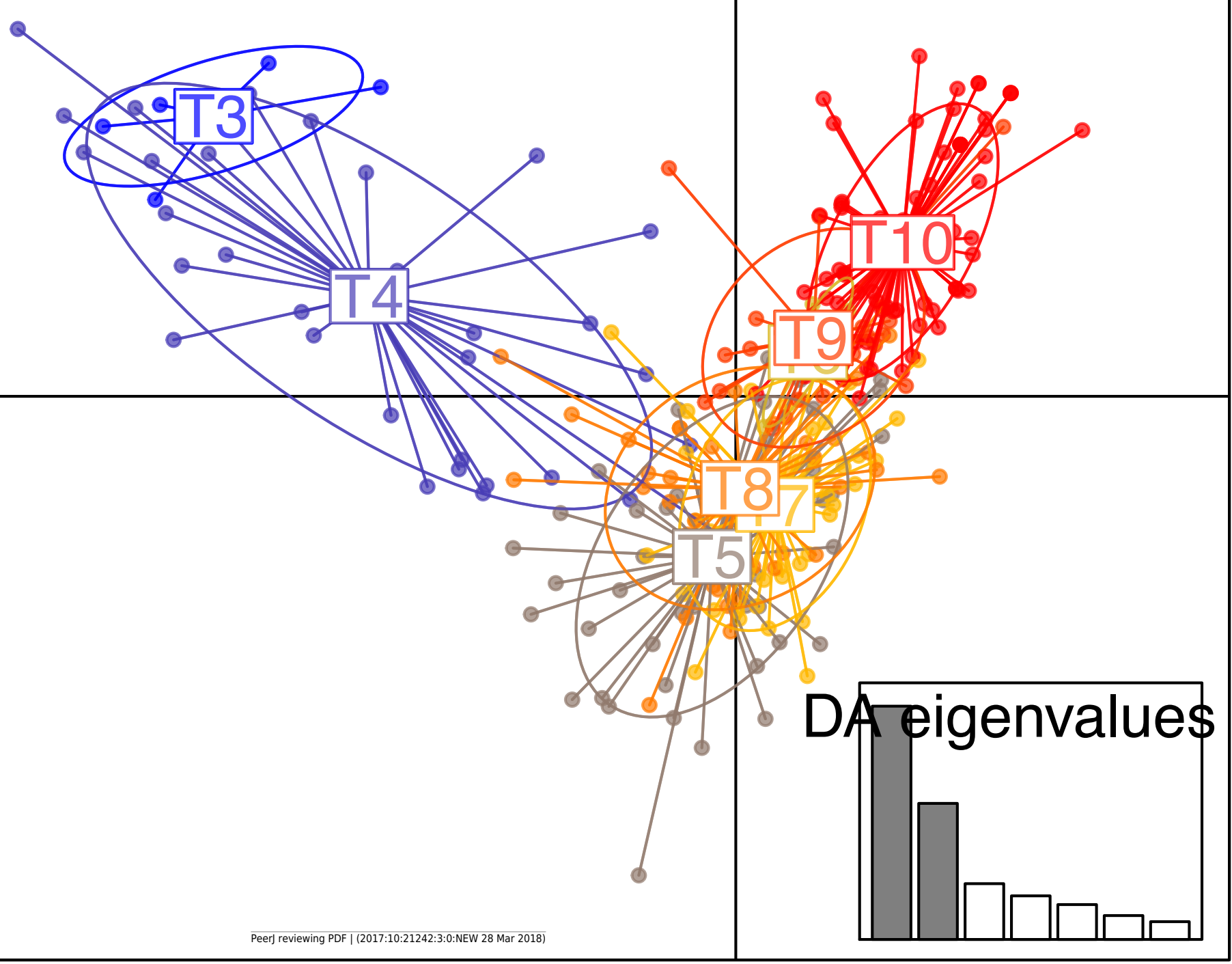




\section{Figure 7 (on next page)}

Spatial autocorrelation analysis of Loiselle kinship coefficient (Loiselle et al. 1995).
A) All tiles: correlogram performed for all the individuals within the cave B-G) correlogram performed for for each tiles with enough numbers of settlers (T4, T5, T7, T8, T9 and T10). Grey lines represent 95\% confidence intervals. 

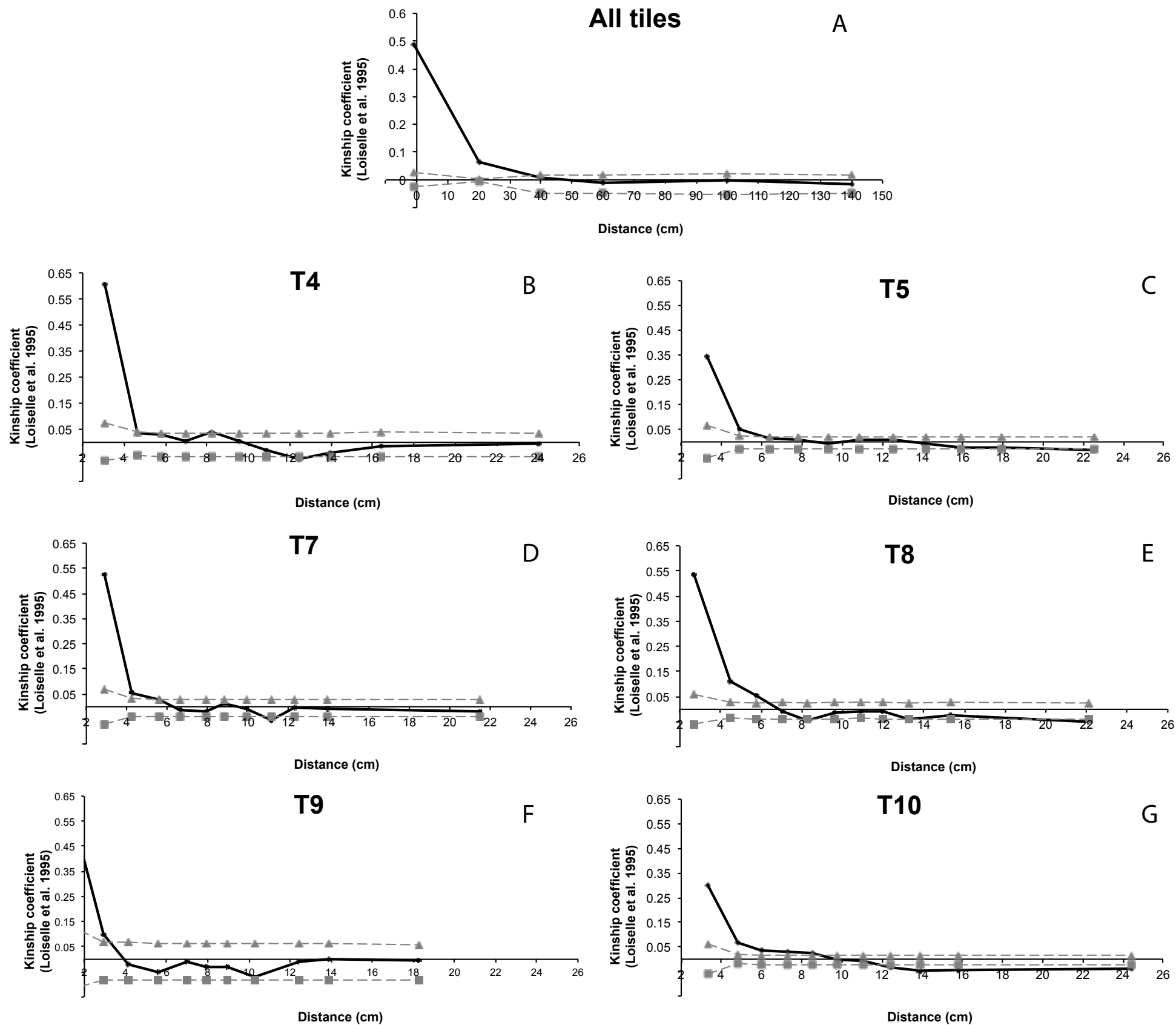


\section{Table $\mathbf{1}$ (on next page)}

Locus characteristics for all the individuals

Number of alleles per locus (Na); null allele frequency ( $r$ ); gene diversity $\left(H_{e}, N e i\right.$ 1973); observed heterozygosity $\left(\mathrm{H}_{0}\right)$; Weir \& Cockerham (1984) estimator of $\mathrm{F}_{\mathrm{IS}}(f)$. * Significant deviation from panmixia after false discovery rate correction at 0.05 (Benjamini \& Hochberg 1995). 
Table 1: Locus characteristics for all the individuals: number of alleles per locus (Na); null allele frequency $(\mathrm{r})$; gene diversity $\left(\mathrm{H}_{\mathrm{e}}\right.$, Nei 1973); observed heterozygosity $\left(\mathrm{H}_{\mathrm{o}}\right)$; Weir \& Cockerham (1984) estimator of $\mathrm{F}_{\mathrm{IS}}(f)$. * Significant deviation from panmixia after false discovery rate correction at 0.05 (Benjamini \& Hochberg 1995).

\begin{tabular}{ccccccc} 
& $\mathbf{N}$ & $\mathbf{N a}$ & $\mathbf{R}$ & $\mathbf{H}_{\mathbf{e}}$ & $\mathbf{H}_{\mathbf{o}}$ & $\boldsymbol{f}$ \\
\hline Cor9 & 286 & 23 & 0.22 & 0.81 & 0.31 & $0.61^{*}$ \\
Mic20 & 289 & 10 & 0.1 & 0.6 & 0.64 & $0.21^{*}$ \\
Mic24 & 283 & 18 & 0.09 & 0.67 & 0.43 & $0.37^{*}$ \\
Mic26 & 283 & 23 & 0.25 & 0.6 & 0.13 & $0.79^{*}$ \\
Cor46 & 218 & 19 & 0.19 & 0.29 & 0.04 & $0.86^{*}$ \\
L7 & 283 & 20 & 0.1 & 0.56 & 0.32 & $0.44^{*}$ \\
Cor58 & 235 & 16 & 0.25 & 0.66 & 0.17 & $0.75^{*}$
\end{tabular}

